\title{
CENTRO CULTURAL Y BIBLIOTECA
}

\author{
Carlos Jiménez Hurtado \\ Juan A. Palacios González de Rivera \\ Juan Parrado Redondo \\ Miguel Riofrío Fadrique \\ Jesús Sanroma Simal
}
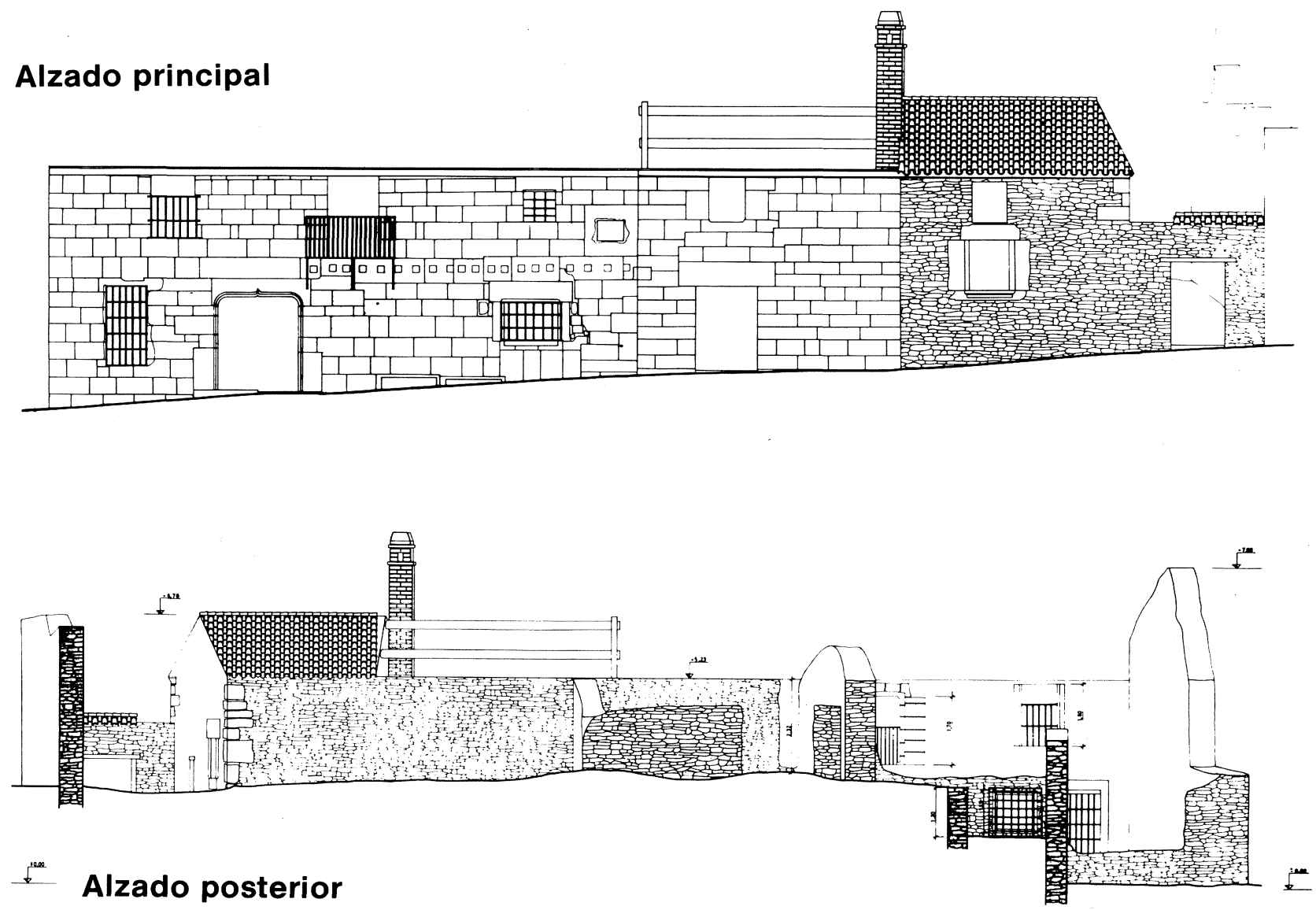

\section{CARACTERISTICAS DEL EDIFICIO}

El edificio a rehabilitar forma parte de los que configuran la plaza del pueblo «Plaza de la Villa».

La construcción es de planta irregular y contaba antiguamente con dos pisos en altura y cubierta de teja árabe.

En la actualidad la cubierta ha desaparecido así como gran parte de la planta superior y muros de cerramiento posteriores, permaneciendo en buen estado la fachada principal.
Dicha fachada está en línea con la de los edificios contiguos, orientada al Este geográfico. Está dividida en dos partes: la primera, de 19,10 m de longitud, es de sillería de granito trasdosada con mampostería de pizarra y la segunda, de $9,20 \mathrm{~m}$, toda ella de mamposteria de la misma piedra con recercados de granito en sus huecos.

Los muros tanto perimetrales como interiores están realizados, al igual que parte de la fachada, con piedra de pizarra del lugar sentada con barro.

Los espesores de dichos muros varían de 0,60 a 1,30 metros. 


\section{Distribución de planta baja}

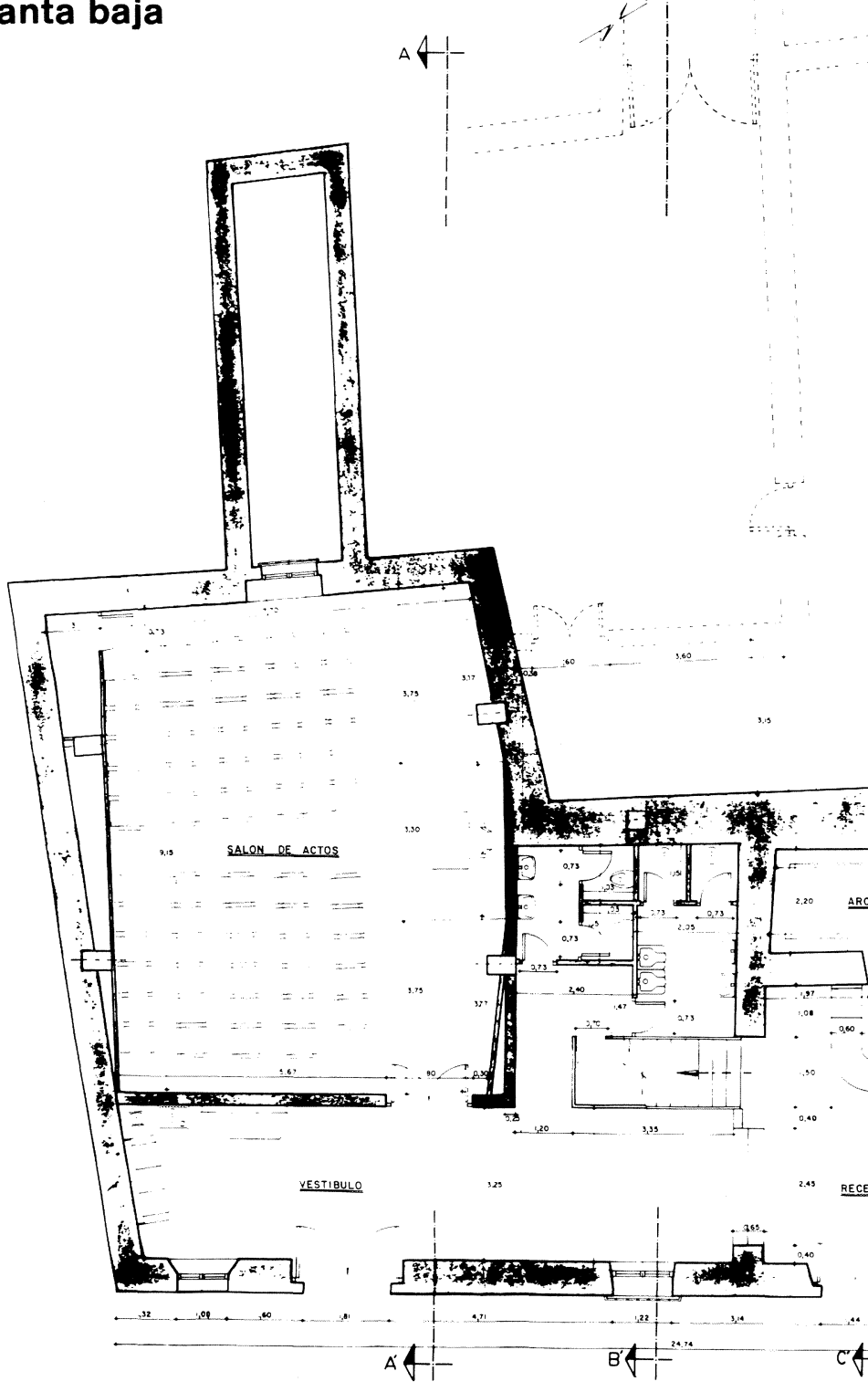

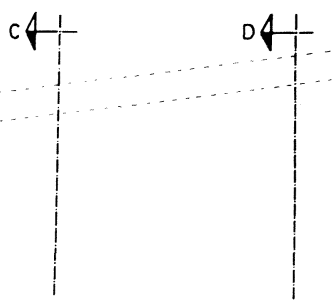

\section{PROGRAMA QUE SATISFACE}

Se destina el edificio, una vez rehabilitado, a centro cultural y biblioteca, ubicándose en la planta baja el vestibulo de recepción, archivo de libros y un salón de actos con capacidad para unas sesenta personas y, en la planta alta, las salas de estudio y lectura.

\section{CONSIDERACIONES CONSTRUCTIVAS}

\section{Elementos que se aprovechan}

Se mantienen la fachada intacta, así como los muros perimetrales, excepto el que se encuentra derruido, que se recompone con ladrillo cerámico macizo por el interior y piedra de pizarra exteriormente.
La chimenea, situada en la sala de recepción, queda en dicho lugar dado su buen estado.

El forjado realizado con viguería de madera, no es aprovechable debido a su avanzado estado de deterioro.

Dicho forjado, en la zona principal del edificio, apoyaba sobre cuatro columnas de granito, habiéndose encontrado en buen estado tan sólo dos de ellas. Las columnas se desmontan pasando a formar parte del porche de acceso al jardín. Las viguetas de forjado, en buen estado, sirven para la formación de la estructura de cubierta del mismo porche.

El resto de los elementos se derriba y los materiales susceptibles de nueva utilización se almacenan para cuando llegue el caso. 


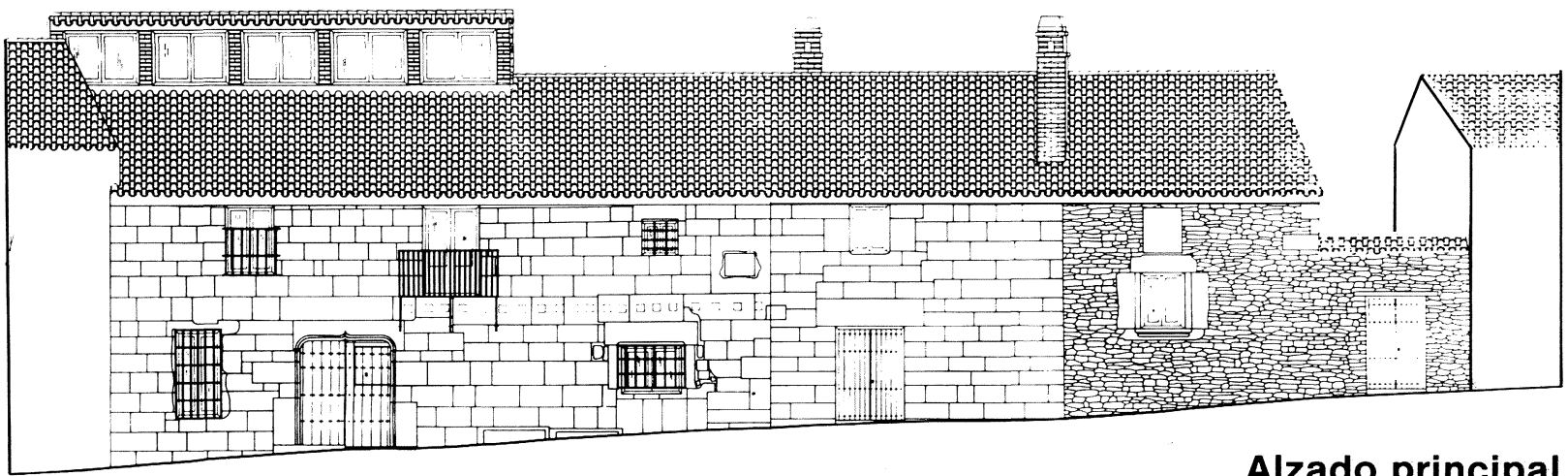

\section{Alzado principal}

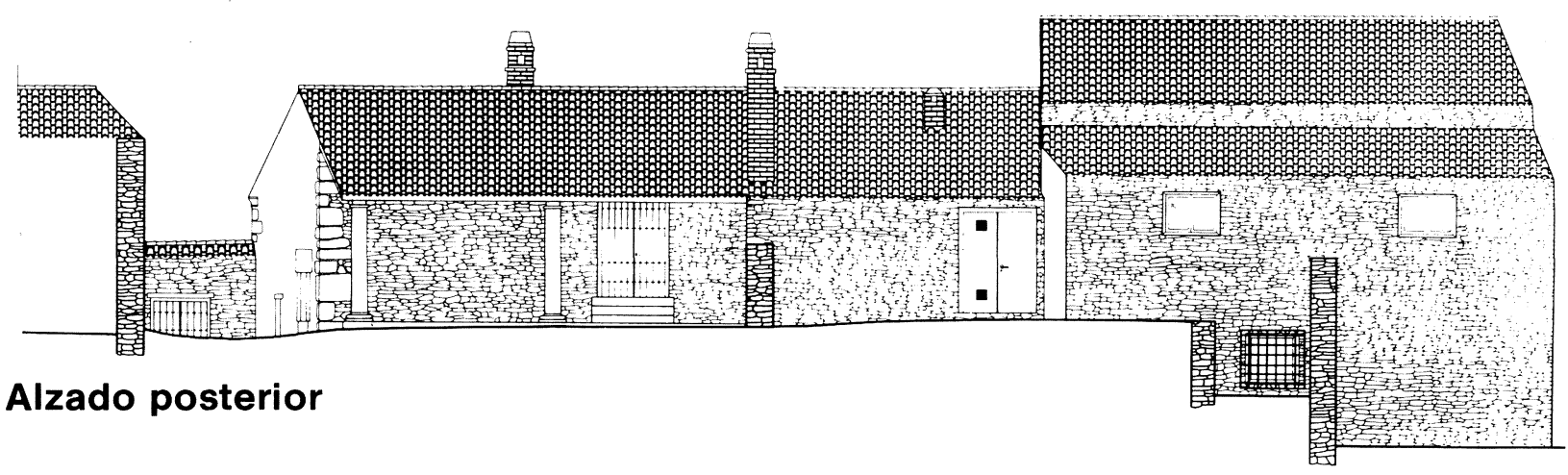

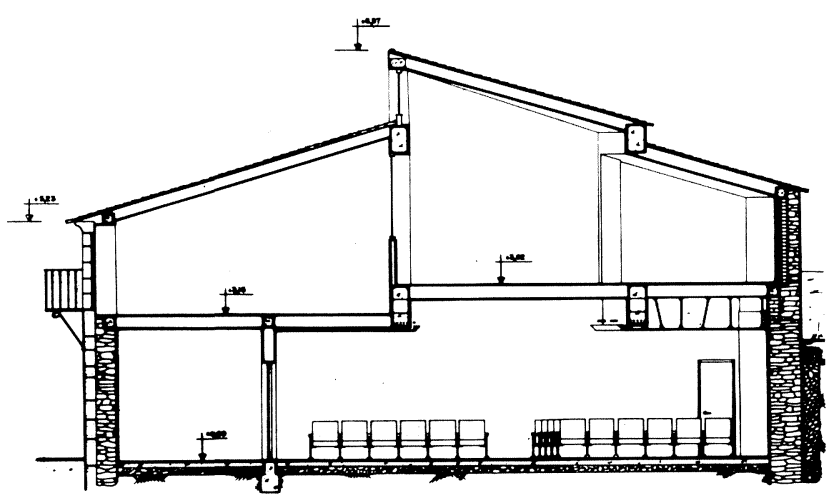

Sección A-A'

\section{ESTRUCTURA}

En el momento de dar la solución más acertada a la estructura nos encontramos algunos inconvenientes tanto funcionales como constructivos:

- La zona idónea para situar el salón de actos es la sala que contaba antiguamente con las cuatro columnas de granito que, por motivos de visibilidad en dicho salón, no pueden ser repuestas ni colocar ningún tipo de pilar o soporte.

- El vano a cubrir es de nueve metros de luz y los muros perimetrales existentes, como se dijo anteriormente, son de mamposteria tomada con barro.

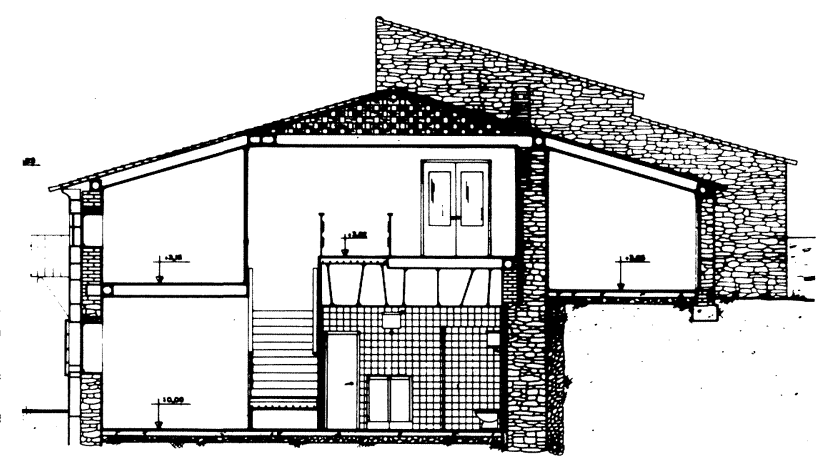

Sección B-B'

- También es un inconveniente la escasa altura disponible.

La cota de cornisa sobre pavimento de planta baja es de $5,23 \mathrm{~m}$ y una vez deducido los espesores de forjados y decuelgue de vigas, resulta insuficiente el espacio de suelo a techo para la realización del salón de actos en planta baja y biblioteca en la alta.

La solución adoptada, en base a hormigón armado, consiste en la realización del forjado en dos alturas y la planta alta abuhardillada con un lucernario corrido. Conseguimos de esta manera captar luz natural (muy necesaria pues el suministro eléctrico es por energia solar) así como el volumen necesario. 

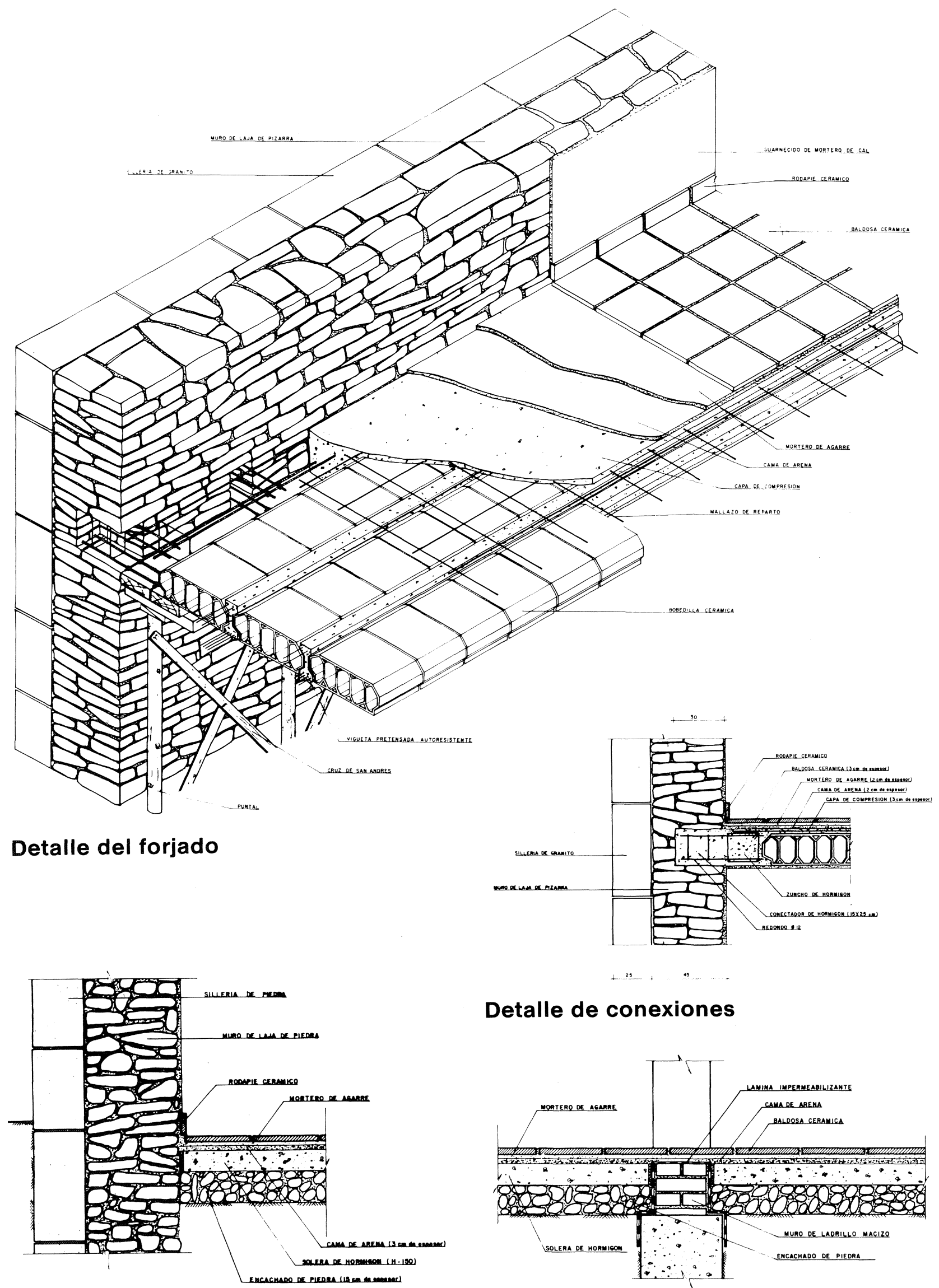

\section{Detalle de conexiones}

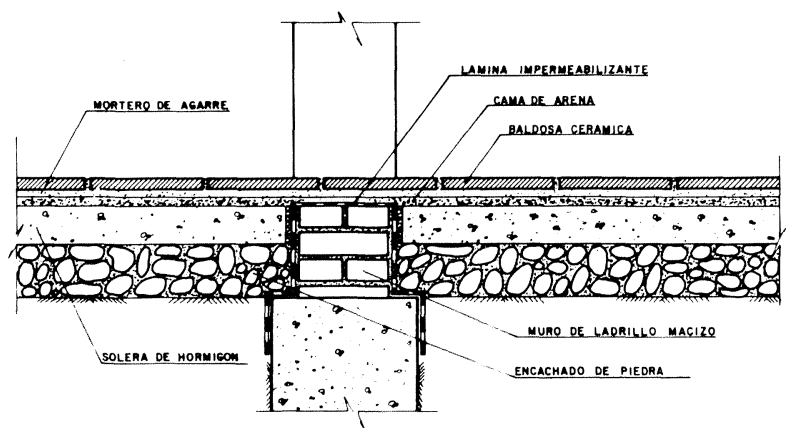



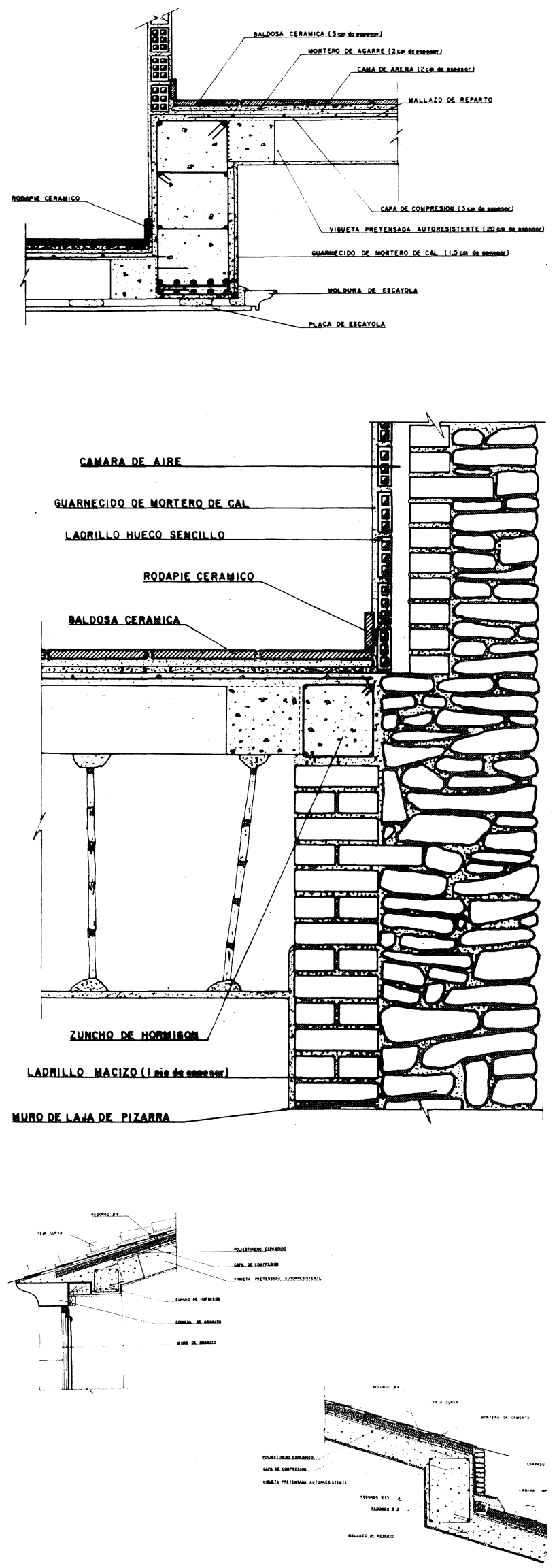

Detalles constructivos
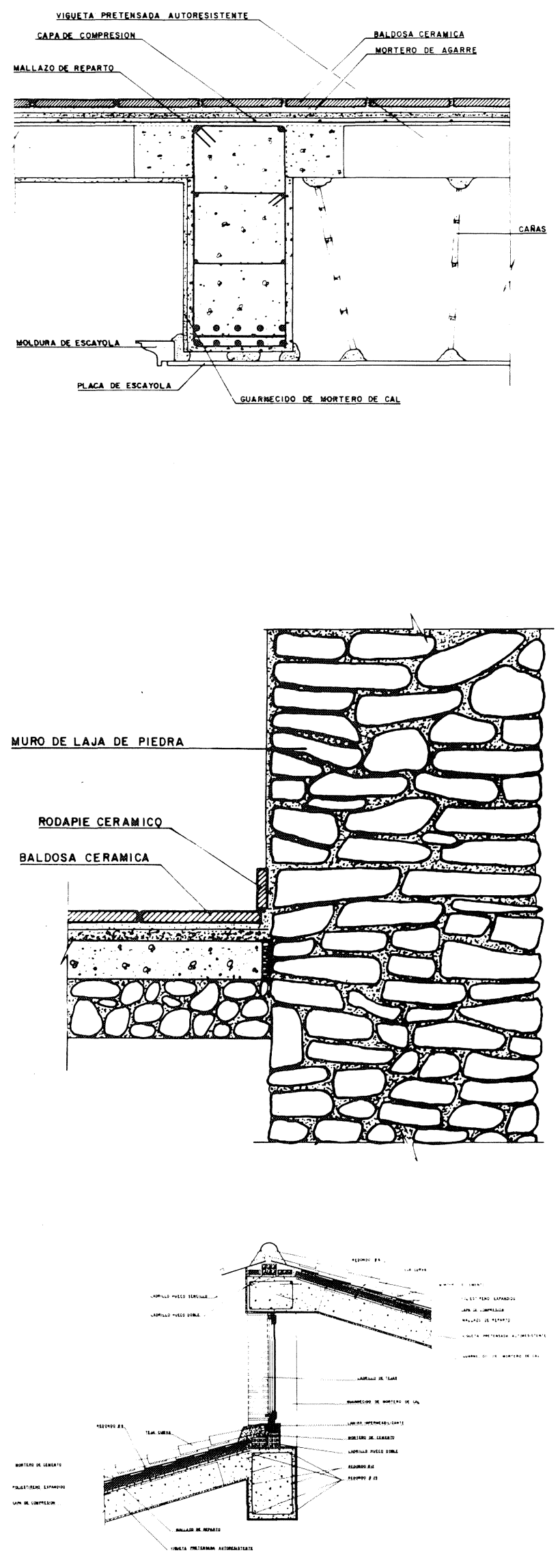

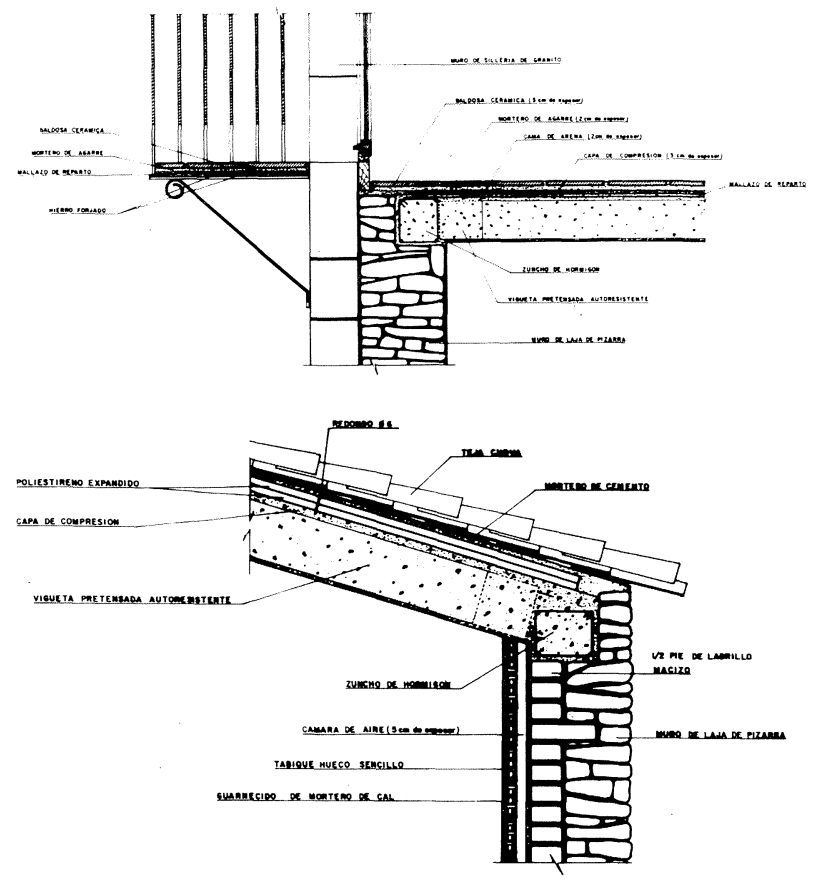

La fachada así como los muros perimetrales se hacen solidarios a la estructura mediante conectores de hormigón armado separados $0,75 \mathrm{~m}$ y de forma y dimensiones que indica el detalle constructivo.

La estructura en la zona del salón está constituida por dos pórticos de hormigón armado, con cimentación por zapatas y viga centradora, y un muro de fábrica de ladrillo macizo de un pie de espesor con cimentación por zanja corrida, así como por los muros perimetrales existentes.

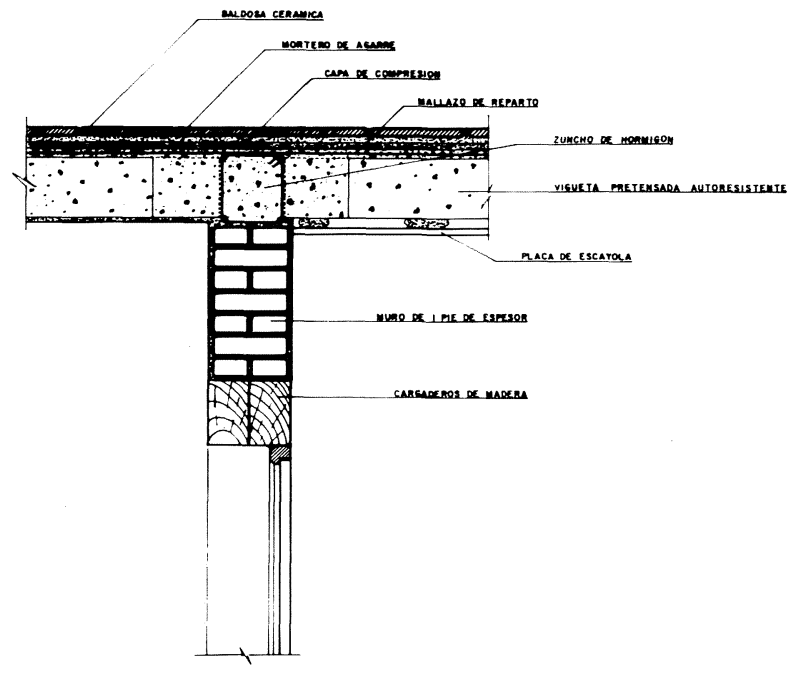

Detalles constructivos

En el resto del edificio la estructura se compone de vigas planas de hormigón armado embebidas en el forjado, que apoyan sobre muros resistentes de ladrillo o sobre los ya existentes.

El forjado y la cubierta se realizan con viguetas pretensadas autorresistentes de hormigón armado y bovedilla cerámica.

Aportamos los detalles constructivos de algunas de las soluciones constructivas adoptadas que hemos creido de interés. 